\title{
Developmental Systems Theory as a Process Theory ${ }^{1}$
}

\section{Paul Griffiths and Karola Stotz}

\begin{abstract}
Griffiths and Russell D. Gray (1994,1997, 2001) have argued that the fundamental unit of analysis in developmental systems theory should be a process - the life cycle - and not a set of developmental resources and interactions between those resources. The key concepts of developmental systems theory, epigenesis and developmental dynamics, both also suggest a process view of the units of development. This chapter explores in more depth the features of developmental systems theory that favour treating processes as fundamental in biology and examines the continuity between developmental systems theory and ideas about process in the work of several major figures in early $20^{\text {th }}$ century biology, most notable C.H Waddington.
\end{abstract}

\section{Introduction}

Developmental Systems Theory (DST) builds on a long tradition of ideas about the systems nature of development amongst biologists and psychologists, predominantly from workers in the field of developmental psychobiology. Elements of DST are derived from C. H. Waddington's ideas about developmental systems (Waddington 1952) and the 'epigenotype' (Waddington 1942), from Daniel Lehrman's influential critique of the idea of innate behavior (Lehrman 1953), from Gilbert Gottlieb's theory of probabilistic epigenesis (Gottlieb 2001), and from Susan Oyama's The Ontogeny of Information (Oyama 1985). Developmental psychobiologists Donald Ford and Richard Lerner integrated many of these ideas into a formal framework in their book Developmental Systems Theory (Ford and Lerner 1992).

DST analyses development, heredity and evolution in a way that avoids dichotomies of nature versus nurture, genes versus environment, and biology versus culture. In this framework development (ontogeny) is the reconstruction of a life cycle using resources passed on by previous life cycles. DST takes heredity to encompass both the stability and plasticity of biological form, which are complementary aspects of the recurrence and modification in each generation of a system of genetic, epigenetic and exogenetic developmental resources (Stotz and Griffiths In Press). The prime focus of a DST account of evolution is the life cycle, the series of events that occurs in each generation of a lineage. The process of evolution is the differential reproduction of variant life cycles. The end of one life cycle and the beginning of the next is marked by the reconstruction of the various mechanisms that allow the life cycle to

\footnotetext{
1 To appear in: Daniel J. Nicholson and John Dupre (eds) Everything Flows: Towards a Processual Philosophy of Biology. Oxford, NY: Oxford University Press
} 
reproduce itself from relatively simple resources. The replication of genes is simply one aspect of the replication of a life cycle. Many classes of developmental resource are replicated: genes, methylation patterns, membrane templates, cytoplasmic gradients, centrioles, nests, parental care, habitats and cultures are all at least partly constructed by past generations, and interact to construct future generations.

Developmental systems theory attracted the interest of philosophers of biology in the 1990s, mostly in response to the work of Susan Oyama (Godfrey-Smith 2000; Gray 1992; Griffiths and Gray 1994; Moss 1992; Robert, Hall, and Olson 2001). However, whilst most scientific work in the developmental systems tradition was on behavioral development, including child development, philosophical discussion of DST focused on its implications for 'gene centered' views of molecular developmental biology and evolutionary biology. In this vein, Kim Sterelny, Michael Dickison, and Kelly Smith (1996) proposed to assimilate developmental systems theory to the replicator/interactor view of evolution of Richard Dawkins (1976) and David Hull (1988). They suggested that the evidence and arguments used to support DST could be accommodated by the concession that there are some non-genetic replicators in addition to the genetic replicators. Evolution is the result of competition between an extended class of replicators.

The 'extended replicator' approach was rejected by developmental systems theorists Griffiths and Gray (1997), who pointed to some paradoxical consequences of trying to describe developmental systems and their evolution in a replicator framework. A developmental system includes a 'developmental niche' that contains reliably inherited developmental resources needed to reconstruct that developmental system or to modify it in the case of phenotypic plasticity. Some of the resources that make up the developmental niche are actively constructed by the parents, such as breast milk or the incubation mounds built by male Brush Turkeys (Goth 2004). Others are constructed by the activity of many conspecifics, and not only the parents, like the flock structure required for normal behavioural development in Cowbirds (West and King 2008). But some merely persist, independent of the activities of previous generations of the developmental systems, like the territories inherited by male Scrub Jays from their fathers (West, King, and Arberg 1988, 49). All these resources are potentially part of the evolved developmental system: "There is a fundamental similarity between building a nest, maintaining one built by an earlier generation, and occupying a habitat in which nests simply occur (for example, as holes in trees). In all three cases, there may be an evolutionary explanation of the interaction of the nest with the rest of the developmental system" (Griffiths and Gray 1994, 291).

Griffiths and Gray used examples of habitat and host imprinting to show that one lineage can outcompete another even when the feature in which the two lineages differ falls into the category of 'merely persistent' resources (Griffiths and Gray 1994, 288-290). They reiterated this point in 1997 to rebut the objection that habitat and host associations themselves do not evolve by natural selection, only the 
behaviors that produce habitat and host associations. This objection fails because populations with exactly the same behavioral mechanism for habitat or host imprinting may differ in their level of fitness because of the specific persistent resource to which they (re)establish a relationship: "In cases of host imprinting in parasitic insects or cuckoos... much of the rest of the parasite group's evolution may result from the success of lineages with one relationship rather than another" (Paul E Griffiths and Gray 1997, 485).

The relationship between a developmental system and a persistent resource can explain aspects of both development and evolutionary success. But the persistent resource itself is not replicated in development, nor does it increase its representation relative to alternatives as a result of the evolutionary success of the system, so the persistent resource cannot be treated as a replicator. What is replicated, and may increase in representation, is the relationship between system and resource. Griffiths and Gray (1997) argued that treating these relationships as replicators independent of their relata would be a reductio ad absurdum of the replicator concept. DST offers a less paradoxical treatment of persistent resources:

"We conceive of an evolving lineage as a series of cycles of a developmental process, where tokens of the cycle are connected by the fact that one cycle is initiated as a causal consequence of one or more previous cycles, and where small changes are introduced into the characteristic cycle as ancestral cycles initiate descendant cycles. The events which make up the developmental process are developmental interactions - events in which something causally impinges on the current state of the organism in such a way as to assist production of evolved developmental outcomes." (Griffiths and Gray 1994, 291)²

A process ontology for DST allows it to reconcile two otherwise paradoxical facts: some components of the evolved developmental system persist without reference to the rest of the system, but the presence of these components in the system can be explained by natural selection. These facts cease to seem paradoxical if we focus on how life cycles - processes rather than systems of entities - reproduce themselves and on how variant life cycles reproduce themselves more or less effectively. It is the developmental process that replicates itself across the generations, making use of persistent resources as well as resources created by earlier cycles of that process. Re-establishing or breaking a relationship to a

\footnotetext{
2 This proposal has a parallel within the replicator tradition, namely G. C. Williams' view of the organism as a region of space-time structured by evolved information (Williams 1992). By this stage of his career Williams had abandoned the idea of objects competing to replicate themselves in favour of the differential replication of information, an approach that lends itself more easily to a process perspective, and which would seem to accommodate the replication of relationships.
} 
persistent resource, for example by becoming imprinted on a new habitat, is an event that is part of a developmental process.

\section{Process biology}

Griffiths and Gray argue that the fundamental unit of analysis in DST is a developmental process. This process is better described as a life cycle, since it encompasses the entire period between conception and death. Does this mean that DST is a form of process biology? In this chapter we will argues that it does. As a first step we discuss the inspiration that many early $20^{\text {th }}$ century biologists drew from process philosophy, and ask which if any of their ideas correspond to those found in DST. A direct link between DST and these earlier thinkers is the embryologist, developmental geneticist and theoretical biologist Conrad Hal Waddington (1905-1975) whose ideas have been cited by many advocates of DST. In The Evolution of Developmental Systems (1952) Waddington describes his understanding of physiology, developmental and evolution as nested processes:

Biologists have always been forced by their subject matter to take time seriously. But it is only gradually that they have realised to the full the necessity always to consider living things as essentially processes, extended in time, rather than static entities.

The day-to-day activities of living things are carried on by processes which occur anything from a fraction of a second to an hour or two... [the organism] is gradually carried along through another series of processes, those of development, each phase of which occupies a time which is fairly long compared with the life-cycle. Each life-cycle is again nearly circular, and gives rise to new animals, the descendant generation... The accumulation of such changes gives rise to the slow process of evolution, which is on a still larger scale than either the physiological or developmental ones. (Waddington 1952, 155)

Waddington was deeply influenced by the process philosophy of Alfred North Whitehead, as were many of his British contemporaries, such as biochemist Joseph Needham, theoretical biologist J.H Woodger, and the leading Cambridge behavioral biologist W.H. Thorpe (Abir-Am 1987; for Thorpe's views, see Thorpe 1956). Whitehead's influence on biology was equally strong in Australia, including the Nobel prize winning immunologist Frank Macfarlane Burnet (Anderson and Mackay 2014), geneticist and ecologist L. Charles Birch (Birch 1965) and geneticist Wilfrid E. Agar. It was Agar (1882-1951) who introduced Australian biologists to process philosophy, through works such as 'Whitehead's Philosophy of Organism: an Introduction for Biologists' (Agar 1936). Agar sought to convince his fellow biologists that process philosophy was a good framework for biological research and so his work is particularly useful when we ask what aspects of this older enthusiasm for process thought are relevant to DST. 
There are some aspects of Whitehead's thought that were important to these biologists, but which have little relevance in the current context. Whitehead rejected the idea that the mental must be explained in physical terms, insisting instead on a monistic 'panexperientialism'. Agar noted that "The conception that the world, including the physical world, is composed of entities which are "drops of experience" or feelings will seem to many people a strange one" $(1936,18)$. He hastened to reassure biologists that, "We must bear in mind that 'feeling' is here used throughout as the purely general term for any kind of acting or being acted upon, in such a way that the make-up of the subject is affected" (1936, 18; quoting Emmet $1932,142)$. Through these aspects of his system Whitehead offered biologists a way to make room for consciousness in the physical world, as well as a route to reconcile science and religion, and for many biologists this was an important source of their attraction to Whitehead (Bowler 2014).

However, as historian Peter Bowler has noted, "Waddington had no interest in encouraging scientists to revive an interest in religion" (Bowler 2014, 80). His interest in Whitehead's metaphysics was strictly biological. The lessons he derived from Whitehead were that biological phenomena should be explained at the level of the whole system, and that the reconstruction of form in development should be explained dynamically, not by the transmission of something that concretely embodies that form. In his autobiography he outlined some specific impacts on his work in embryology and genetics:

"In the late '30s I began developing the Whiteheadian notion that the process of becoming (say) a nerve cell should be regarded as the result of the activities of a large number of genes, which interact together to form a unified "concrescence". ... Again a few years later it had become apparent that "gene-concrescence" itself undergoes processes of change; at one embryonic period a given concrescence is in a phase of "competence" and may be switched into one or other of a small number of alternative pathways of further change but the competence later disappeared and if you've missed the bus the switch won't work. ... If I had been more consistently Whiteheadian, I would probably have realized that the "specificity" [the fact that the switch sends the cell down a particular developmental pathway] involved does not need to lie in the switch at all but may be a property of the "concrescence" and the way in which it can change. Because of course what I have been calling by the Whiteheadian terms [sic] "concrescence" is what I have later called a chreod [canalised developmental trajectory]" (Waddington 1975, 9-10).

As we will see below, what makes DST a process theory is that it seeks to explain developmental outcomes as the result of a dynamic process in which some of the interacting factors are products of earlier stages of the process, rather than as the result of the arrangement of pre-existing factors into a static mechanism. Even when factors exist independently of the developmental process, they are drawn into it and made part of a developmental 'system' by the unfolding process, as we have already discussed 
above. It is the process that defines the system. In these respects DST is the direct inheritor of Waddington's process biology.

Another reason biologists were drawn to Whitehead was his organicism - the idea that collectives have an enduring identity that cannot be reduced to the continuity of their parts. This was at the heart of Agar's interest in Whitehead:

"It is in [Whitehead's] conception of the unity of a nexus that we strike the main idea of theories of organism as usually understood by biologists, namely, the idea that the whole is more than the sum of its parts, and indeed imposes its own character on its parts. As Ritter puts it, the whole acts causally on its parts, as well as being acted on causally by its parts. This is only understandable if we get away from the idea of substance and fix our attention on process. We must not think of the molecule as composed of ultimate particles of matter in motion. But the molecule is a pattern of processes, and each constituent process conforms to its place in the pattern, and resists factors tending to alter it." (Agar 1936, 29; see also Agar 1943)

Agar finds in Whitehead an account of the identity of an organism that is reassuringly Darwinian:

'It is cardinal to Whiteheads' philosophy that the subjective aim of an actual entity is not merely at self-realization, but at self-realization as an agent creative of other entities like itself, or at least of the production in other actual entities of feelings like its own." (Agar 1936, 22)

Elsewhere, Agar identifies 'subjective aim' with final causation, so part of what he is saying here is that the $\operatorname{telos}^{3}$ of an organism is to reproduce itself.

We do not think that the details of Agar's Whiteheadean organicism contain much of relevance to DST, but the issue he is addressing - the identity of processes through time and their distinctness from one another - is a vital one for DST. A biological individual is a process which may intersect with other organismic processes, but which has a principle of identity that marks just this series of events out as one biological individual. DST thus requires an account of what is known in process philosophy as 'genidentity' or identity as continuity of organization. This principle of identity also determines, by identifying a process, the boundaries of the developmental system - the matrix of resources required for that process to proceed to completion. We return to this issue in section 6 , where we will see that the identity of a developmental process, and its distinction from other individual processes is indeed given by its telos, though doubtless not in the exact sense envisaged by Agar.

\footnotetext{
${ }^{3}$ Its end or purpose; that for the sake of which the organism exists and acts.
} 


\section{Process in the developmental systems tradition}

"An animal is, in fact, a developmental system, and it is these systems, not the mere adult forms which we conventionally take as typical of the species, which becomes modified during the course of evolution." (Waddington 1952, 155)

Waddington's idea of a developmental system and his early attempt to explain development as the result of the dynamical structure of that system is an important precursor of DST (Griffiths and Tabery 2013). However, he remained a profoundly gene-centered thinker. The dynamical structure is an 'epigenotype' the global expression of all the organism's genes and it explains, through the presence of 'creods', the resistance of some developmental trajectories to environmental perturbation. Waddington does not embrace the idea that the evolved developmental system actually includes aspects of the environment rather than merely being designed to function in an environment and cope with its variations.

For this central theme in DST we must turn to the comparative psychologist Daniel S. Lehrman, perhaps the single most important figure in the development of DST and indeed of the scientific field of developmental psychobiology:

'Natural selection acts to select genomes that, in a normal developmental environment, will guide development into organisms with the relevant adaptive characteristics. But the path of development from the zygote stage to the phenotypic adult is devious, and includes many developmental processes, including, in some cases, various aspects of experience' (Lehrman 1970, 36)

Lehrman was not a Whiteheadean and so it is all the more significant that his efforts to place development at the heart of the study of animal behavior led him to adopt a process view of the organism:

The use of "explanatory" categories such as "innate" and "genetically fixed" obscures the necessity of investigating developmental processes in order to gain insight into the actual mechanisms of behavior and their interrelations. The problem of development is the problem of the development of new structures and activity patterns from the resolution of the interaction of existing ones, within the organism and its internal environment, and between the organism and its outer environment. At any stage of development, the new features emerge from the interactions within the current stage and between the current stage and the environment. The interaction of which the 
organism develops is not one, as is so often said, between heredity and environment. It is between organism and environment! And the organism is different at each stage of its development. (Lehrman 1953, 435, italics in original.)

Lehrman is not merely being pedantic in insisting that organisms, not genes, interact with environments. The impact of a genetic or environmental factor at some point in development depends on how the organism has developed up to that point. It is an organism at some stage of development that interacts with both genes and environment to produce the next stage of development. Development is essentially a dynamic process in which, as Waddington insisted, we need to take account of time, as well as a list of ingredients.

The historical contingency of individual development was at the heart of what developmental psychobiologist Gilbert Gottlieb, another major source for DST, called the 'developmental psychobiological systems view' (Gottlieb 1970). Gottlieb contrasted what he called 'probabilistic epigenesis' with what he saw as the prevailing view of 'predetermined epigenesis'. The latter concept, he argued, covered up the persistence of preformationist thought in modern biology (Gottlieb 2001, see also Robert 2004). According to Gottlieb, "the cause of development - what makes development happen - is the relationship of the components, not the components themselves" (Gottlieb 1997, 91). The impact of any causal factor depends on the order in which the system is exposed to that and other factors. This places limits on our ability to predict the results of development from a list of measured factors. Gottlieb's influence lives on in DST's emphasis on contingency. ${ }^{4}$

The idea of a formal Developmental Systems Theory is due to Donald Ford and Richard Lerner (1992), who identify two core theses of DST. The first, which they call "developmental contextualism", is derived from Gottlieb's concept of probabilistic epigenesis. Development proceeds at several levels - for example, gene expression, the formation of tissues, and the state of the environment - and the interactions between levels are the prime focus of research, rather than treating one level as focal and the others as background against which it unfolds. Developmental contextualism is a modern version of the epigenetic, as opposed to predeterminist, view of development Their second core thesis is "dynamic interactionism", which they contrast to conventional, "static interactionism". This reflects Lehrman's distinction between organism-environment and gene-environment interaction quoted above. Ford and Lerner regard interaction as an ongoing process that can transform the interactants themselves. In other words, the parts that interact with each other and with the developmental system are products of the developmental system. Overall, Ford and Lerner present a thoroughly processual view of the

\footnotetext{
4 To the best of our knowledge, Gottlieb was not influenced by Whitehead, but he did acknowledge John Dewey as a major source of inspiration (Griffiths and Tabery 2013), and Dewey was acknowledged by Whitehead as an important influence.
} 
developmental system in which we can see the same ideas that we encountered in Waddington and which he claimed to have derived from Whitehead.

This process view of development led to the radical reformulation of the distinction between nature and nurture proposed by Susan Oyama (2002). In the conventional picture of (static) gene-environment interaction nature and nurture are simply interacting causes. Genes, or genes plus 'epigenes', represent nature. The environment represents nurture. Added together they cause development. In DST, however, nature and nurture are product and process. Nurture is the interaction between the current state of the organism and the resources available to it - environmental and genetic. The nature of the organism at each stage is simply the state of the organism - including the modified state of its genome and of its developmental niche, both of which have been transformed by earlier processes of nurture. Oyama rejects the very idea that nature exists separate from and before nurture. One way she expresses this is by insisting that the developmental information expressed in the organism is not present in the starting point of development, but is itself created by the process of development, through feedback from the current state of the organism to the states of the resources that will influence future development. This is what she means by the 'ontogeny of information'.

In The Ontogeny of Information (1985) Oyama pioneered the parity argument or 'parity thesis' concerning genetic and environmental causes in development (see also Griffiths and Gray 1994; Griffiths and Gray 2005; Griffiths and Knight 1998; Stotz 2006; Stotz and Allen 2012). Oyama relentlessly tracked down failures of parity of reasoning in earlier theorists. The same feature is accorded great significance when a gene exhibits it only to be ignored when a non-genetic factor exhibits it. When a feature thought to explain the unique importance of genetic causes in development is found to be more widely distributed across developmental causes, it is discarded and another feature is substituted. Griffiths and Gray (1994) argued in this spirit against the idea that genes are the sole or main source of information in development. Other ideas associated with 'parity' are that the study of development does not turn on a single distinction between two classes of developmental resources, and that the distinctions useful for understanding development do not all map neatly onto the distinction between genetic and non-genetic. Ulrich Stegmann has argued that because DST has not identified a single, essential way in which genetic and non-genetic resources must be treated with parity of reasoning the idea of parity is too vague to be useful (Stegmann 2012). It is hard to know what to make of this criticism. Other critics of DST have dismissed parity as the wildly holistic view that no distinctions of any kind can be made amongst developmental causes: "Parity arguments then claim that picking out one cause, when in fact there are many, cannot be justified on ontological grounds because, after all, causes are causes" (Waters 2007, 
533). ${ }^{5}$ Developmental systems theorists have repeatedly rejected this interpretation and provided examples of ways in which one developmental cause can be more significant than another in ways consistent with DST (Oyama 2000; Griffiths and Knight 1998; Griffiths and Gray 2005). In recent work, Griffiths et al have constructed a quantitative measure of relative causal contribution and used it to assess the parity thesis in specific cases (Griffiths et al. 2015).

So the ideas that Waddington derived from process philosophy can be found in all the major figures who inspired and developed DST. In the next section we discuss in more detail two core ideas that define DST as a distinctive approach to development and argue that both support the idea that the fundamental unit of analysis for DST is the developmental process or life cycle.

\section{Core ideas in DST: Epigenesis and developmental dynamics}

Two ideas recur in all the authors described above, and are at the heart Developmental Systems Theory: epigenesis and developmental dynamics (Griffiths and Tabery 2013). Both of them support the idea that the central focus of DST should be on developmental processes rather than on sets of objects (developmental resources).

\section{Epigenesis}

The term 'epigenetics' is derived from the process of epigenesis. "As a continuation of the concept that development unfolds and is not preformed (or ordained), epigenetics is the latest expression of epigenesis" (Hall 2011, 12). It was invented by Waddington as a fusion of 'epigenesis' and 'genetics' to refer to the processes by which genotype gives rise to phenotype and to the study of those processes (Waddington 1942). Waddington suggested that existing knowledge from experimental embryology supported a view of how genes were connected to phenotypes broadly in line with the older idea of epigenesis. The interaction of many genes produces an emergent level of organization that Waddington called the 'epigenotype' and development is explained by the dynamics of the developmental system at this level.

Waddington's 'epigenotype' was a global expression of the genetic causal factors that influence development. The effect of changing any one gene depended on how it interacted with the rest of the system. The epigenotype as a whole interacted with the environment to determine the phenotype. DST

\footnotetext{
5 For other examples, see (Weber 2006, 607; Thornhill 2007, 206; Rosenberg and McShea 2008, 174; 0kasha 2009, 724; Woodward 2011, 249; French 2012, 197). Okasha calls this kind of wild holism 'causal democracy', a term introduced by Philip Kitcher (2001). Kitcher's principle of causal democracy states that biology should not assume that genes are the most significant causes, but assess the issue empirically on a case-by-case basis. It is thus very similar to Oyama's parity thesis, and neither is committed to any kind of holism!
} 
expands this vision to include non-genetic factors that influence development. The epigenotype is replaced by a more inclusive vision of a developmental system, a global expression of all the causal factors that influence development. The developmental system still does not determine a unique phenotype, both because development is a probabilistic process, as Gottlieb emphasized, and because development is plastic by design. The environment provides many requirements for normal genome expression (the "ontogenetic niche" of West and King 1987) and thus partly constitutes the developmental system, but the environment also determines the specific values of variables in an individual life cyele and so determines the particular course development will take out of those available to the system. The genome also plays these two roles, as some of these variables are determined by genetic individual differences (see Tabery 2009).

In 1958 the biologist David L. Nanney introduced another sense of 'epigenetics', the sense in which it is primarily used in molecular biology today (Haig, 2004). Epigenetics in this sense is the study of mechanisms that determine which genome sequences will be expressed in the cell. These mechanisms control cell differentiation and give the cell an identity that is often passed on through mitosis. Writing in the year that Francis Crick first stated his 'sequence hypothesis' that the order of nucleotides in DNA determines the order of amino acids in a protein and thus encodes the biological specificity of the protein (Crick, 1958), Nanney wrote that, "On the one hand, the maintenance of a 'library of specificities,' both expressed and unexpressed, is accomplished by a template replicating mechanism. On the other hand, auxiliary mechanisms with different principles of operation are involved in determining which specificities are to be expressed in any particular cell. ... they will be referred to as 'genetic systems' and 'epigenetic systems'" (Nanney 1958, 712).

Epigenetics in this narrower, modern sense allows a major role for the environment in development: "As the past 70 years made abundantly clear, genes do not control development. Genes themselves are controlled in many ways, some by modifications of DNA sequences, some through regulation by the products of other genes and/or by [the intra- or extra-cellular] context, and others by external and/or environmental factors" (Hall 2011, 12). The regulated expression of the coding regions of the genome depends on mechanisms that differentially activate and select the information in coding sequences depending on context. Biological information is distributed between the coding regions in the genome and regulatory mechanisms, and the specificity manifested in gene products is the result of a process of 'molecular epigenesis' (Stotz 2006; Griffiths \& Stotz 2013).

So the idea of epigenesis is alive and well in contemporary biology. As Waddington argued, developmental outcomes are to be explained at the level of the whole system and not by single causes that 'encode' or 'instruct' that outcome (for an influential restatement of this view, see Noble 2006). Developmental outcomes are also explained dynamically, as trajectories in a space of possible states of 
genome expression. The role of epigenetic marks in development is to successively differentiate cells as a result of earlier stages of development, making genome expression in a tissue at a time a function of the history of these cells. The complexity of biological networks makes it plausible that in many cases this process will display emergent dynamics that can only be studied through simulation, a point we expand on in the next sub-section.

DST adds to this modern epigenetic vision of development the same thing that it added to Waddington's original vision of epigenetics, namely a constructive role for the environment. The networks that regulate gene expression extend outside the cell and outside the organism. Evolution designs developmental processes that draw these wider resources into the developmental system by reestablishing relationships to them. The presence of suitable external resources is in many cases explained by the activity of parents and of conspecifics more generally ("developmental niche construction" (Griffiths and Stotz 2013), and sometimes by the feed-forward effects of earlier stages of the developmental process itself, as discussed immediately below.

\section{Developmental dynamics}

The idea that development is a dynamic process is central to DST. Ford and Lerner contrast 'dynamic interaction' with a more conventional conception of interaction associated with analysis of variance techniques, such as those used in behavioral genetics (Ford and Lerner 1992). In that 'static interaction' the values of two variables measured before development, such as shared genes and shared environment, are shown to interact with one another. In contrast, dynamic interaction must be studied as a temporally extended process. For example, in Celia Moore's iconic work on sexual development in male rat pups, male sexual development depends on differential licking of the genital area of male and female pups by the mother. But this response to male pups depends on differences in their urine, which are the result of earlier processes of sexual differentiation (Moore 1984,1992). The presence of this environmental influence is a feed-forward from earlier development in the pup itself. The patterns of gene expression that underlie sexual development in the rat arise through interaction with an environment that has been partially structured by an earlier stage of the rat's development. The idea of developmental dynamics embodies one of the basic ideas of process biology, namely that the developmental system is defined, and in part physically produced, by the process of development.

If interaction is a dynamic process, then the temporal dynamics of the interaction may play an independent role in explaining the outcome. This explains why many DST advocates have also been attracted to explanations of developmental which draw on dynamical systems theory (abbreviated as DyST to avoid confusion). Griffiths and Tabery (2013) argue that there is nothing about the basic idea of 
dynamical interaction found in DST that requires the use of DyST. The example of rat development just given, for example, is a sequential mechanism that can be described without using DyST. But in other cases, DyST provides additional explanatory resources (Thelen and Smith 1994; Bechtel and Abrahamsen 2013). Dynamical systems theory exemplifies even more strongly than the bare notion of developmental dynamics the idea that developmental outcomes should be explained at the systems level.

In this section we have argued that the core ideas of DST, epigenesis and developmental dynamics, embody the very same ideas that featured in Waddington's process biology. Developmental outcome are explained at the systems level, and in identifying the components of a developmental system we start with the developmental process, not the other way around. In the next section we develop these ideas further by examining how DST has conceptualized the constituents of developmental systems.

\section{An ontology for DST: genomes, epigenomes and developmental niches}

One of the most controversial features of DST is its conceptualization of the developmental system as an organism-environment system. Rather than an organism developing in an environment, aspects of the developmental environment are part of the developmental system. As well as talking of developmental systems, advocates of DST have talked of sets, collections or matrices of developmental resources and more recently of ontogenetic or developmental niches that provide the developmental context for organisms or genomes.

DST has always resisted the idea that there is a single way to divide the inputs to development that will be useful for every scientific question about development (Hinde 1968; Johnston 1987; Oyama 1985). Instead, distinctions should be introduced locally to suit the question at hand. For some purposes, as an alternative to 'organism and environment' or 'genes and environment', the resources that make up a developmental system can be partitioned into three: genome, the epigenome (chemical modifications of DNA that are transmitted through meoisis), and the developmental niche. Since the fundamental unit of analysis for DST is the complete developmental process, or life cycle, we can think of that process as occurring within, and feeding forward into the construction of, a developmental systems with these three components. Or we can think of the life cycle as consisting of the regulated expression of an epigenetically modified genome through its interaction with a developmental niche.

The genome is a familiar idea, and the epigenome increasingly so. The idea of a developmental niche will be less familiar to many readers. Developmental psychobiologists Meredith West and Andrew King (1987) introduced the term 'ontogenetic niche' to capture the idea that environmental resources form a social and ecological legacy inherited by a developing organism. We have used 'developmental niche' as a synonym for West and King's term (Stotz 2008; Stotz 2010; Griffiths and Stotz 2013). Species-specific 
phenotypes depend on species-typical environments of development. These are often the result of parental activities, but their construction can also involve other conspecifics past and present and, importantly, the offspring itself. The idea of the construction of a developmental niche answers a fundamental question about inheritance - how do parents reliably influence the phenotype of their offspring and promote their healthy development? Organisms do not rely on chance to provide their offspring with the resources for normal development: they actively intervene to modify environments for this end. West and King described the ontogenetic niche as an 'information centre' in the sense that it makes the interaction of organism and environment more specific than it would otherwise be. The idea of an information centre was developed initially to capture the experiences necessary for species-typical learning (Galef and Wigmore 1983). These are the 'aspects of experience' that Lehrman identified as part of the developmental system (Lehrman 1970, 36 and quoted above). However, the idea can be applied to the much broader category of any environmental stimulus that acts as a specific cause of normal development (Griffiths \& Stotz 2013).

Dividing the developmental system into genome, epigenome and developmental niche may be useful in the study of evolution, because it parallels one way to divide mechanisms of heredity. It is now fairly conventional to recognize epigenetic heredity mechanisms as a genuine form of heredity alongside genetic inheritance, although arguments about whether these mechanisms have equal evolutionary significance continue. 6 But DST, like other recent theorists (e.g. Jablonka and Lamb 2005), recognizes a wider range of heredity mechanisms. It is unfortunate that this wider class of mechanisms is often also referred to as 'epigenetic inheritance', making that term ambiguous, as it is used more narrowly to refer only epigenetic marks inherited through meiosis. In earlier work we have suggested keeping 'epigenetic inheritance' for the narrower class of mechanisms and using West and King's term 'exogenetic inheritance' (West \& King 1987, 5) for the broader class of mechanisms. It is this broader class of heredity mechanisms that constructs the developmental niche: "Organisms construct their life cycles through the interaction of the contents of the fertilized egg, the genome and its narrowly epigenetic surroundings, with a 'developmental niche' which is the result of epigenetic inheritance in a wider sense ... 'exogenetic inheritance'...' (Griffiths and Stotz 2013, 5).

\footnotetext{
${ }^{6}$ It if often asserted that epigenetic change will only affect evolution if the changes themselves persist for more than one generation (e.g. Wilkins 2011). But in conventional quantitative genetics the evolutionary significance of genetics does not result from tracking individual alleles from one generation to the next - quantitative genetics does not do this. Instead, Mendelian assumptions let us work out what phenotypes (and hence fitnesses) will appear in the next generation as a function of the phenotypes in the last generation. Epigenetic and exogenetic inheritance both change this mapping from parental phenotype to offspring phenotype, and therefore affect evolution. Both epigenetic and exogenetic inheritance appear in quantitative genetics as 'parental effects': correlations between parent and offspring phenotypes above and beyond correlations between parent and offspring genotypes, which are also not the result of a shared environment independently influencing both parent and offspring. It has long been understood that one-generation parental effects can substantially alter the dynamics of evolutionary models, and change which state a population will evolve to as an equilibrium (Lande and Price 1989; Wade 1998). The argument that epigenetic inheritance needs to be stable for several generations to have evolutionary significance appears to be a non-sequitur.
} 
It is worth noting that this broader, exogenetic form of inheritance may be more stable than narrow epigenetic inheritance. Some exogenetic inheritance occurs through the induction of epigenetic modifications in offspring by parental behavior. This can have long-term, often lifelong, effects on offspring phenotype. In some known cases these offspring phenotypes include the very parental behavior that induced them, so that the offspring reproduce the effect in the next generation, and so forth (Champagne and Curley 2009). These behaviorally transmitted but epigenetically mediated effects contribute to the long-term stabilization of aspects of the developmental niche, and hence may be more long-lived than meiotic epigenetic inheritance.

It is important not to conflate the developmental niche with the 'niche' of niche-construction theory (Odling-Smee, Laland, and Feldman 2003). Niche construction theory concerns the influence of past generations on the selective pressures that act on future generations. This activity partially constructs a selective niche, the set of parameters that determine the relative fitness of competing types in the population. The developmental niche, however, is the set of parameters that must be within certain bounds for an evolved life cycle to occur (or in more traditional terms, for the organism to develop normally). The two niches will often share many parameters. They are, however, conceptually quite distinct. For example, signals from parent to offspring that induce transgenerational adaptive phenotypic plasticity, as when Daphnia signal their offspring to grow additional defenses against predators, are a clear example of developmental niche construction: the parent Daphnia is structuring the developmental environment of its offspring. But this is no more a case of selective niche construction than is the inheritance of an advantageous mutation! The Daphnia embryo is alters itself to fit the selective environment rather than altering the selective environment.

\section{DST as a process theory of the organism}

One reason early $20^{\text {th }} \mathrm{C}$ biologists were drawn to process philosophy was that it offered a 'theory of the organism' - an account of the unity of living systems. Recent interest in process ontologies for biology has revived interest in the concept of 'genidentity' or identity as continuity of organization (Guay \& Pradeu 2015). Distinct stages are stages of the same thing because one developed from the other, rather than because they share some common properties:

[genidentity] says that the identity through time of an entity $\mathrm{X}$ is given by the continuous connection of states through which $\mathrm{X}$ goes. ... In this view, the individual $\mathrm{X}$ is never presupposed or given initially, because the starting point is the decision to follow a specific and appropriate process $\mathrm{P}$, and the individual $\mathrm{X}$ supervenes on this process. ... In other words, for the genidentity view, what we single out as an "individual" is always the by-product of the activity that is being followed, not 
its prior foundation (not a presumed "thing" that would give its unity to this activity). (Guay and Pradeu 2015, 317-18)

Guay and Pradeu here exemplify themes familiar from our earlier discussion of Waddington and Agar. The persistence of biological form should be explained dynamically, not by the transmission of something that concretely embodies that form. The identity of an individual through time is a dynamic continuity of form. If the fundamental unit of analysis in DST is the developmental process, or life cycle, if heredity in DST is a relation between one life cycle and another, and natural selection occurs in populations of life cycles (Griffiths and Gray 2001), then DST needs to give an account of the genidentity of these processes. It needs to say where one developmental process ends and the next begins. This problem arises in a dramatic form when organisms have alternating haploid and diploid phases of comparable length (Godfrey-Smith 2015). Is each phase a life cycle, or is a life cycle the combination of a haploid and diploid phase?

The principle of genidentity of a life cycle also needs to explain how a life cycle can consist of a different series of events from one generation to the next. This problem arises in a dramatic form when a species have a range of substantially different ways to get from conception to death. Some newts, for example, exhibit facultative paedomorphosis in which individuals respond to differences in their environment by either retaining the morphology of their acquatic, larval stage and becoming reproductively mature in that state, or going through metamorphosis to become a terrestrial 'adult' reproductive form (Denoël, Joly, and Whiteman 2005). The same issue arises in principle, however, whenever an organism exhibits adaptive phenotypic plasticity, so that successive life cycles in a single lineage do not contain the same developmental events.

DST has often been criticized for replacing the commonsense idea of an individual organism with a novel and nebulous 'system' (Sterelny, Dickison, and Smith 1996; Merlin 2010; Pradeu 2010; and see the references in fn. 4. ). This criticism has become increasingly unfair over the past twenty years. It is no overstatement to say that conventional theories of biological individuality are in a state of crisis brought on by new empirical and theoretical developments in biology. These include research on evolutionary transitions in individuality, the realization of the extent to which core physiological processes in multicellular organisms are carried out by microbial commensals, the discovery of ever more complex and highly integrated functional associations between microbes themselves, as well as increased attention by philosophers and theoretical biologists to the full diversity of life, in all it's glorious weirdness! The result has been a wave of new work in philosophy and theoretical biology on the nature of individuality, a literature that shows little sign of reaching consensus (Calcott and Sterelny 2011; Pradeu 2012; Ereshefsky and Pedroso 2013; Bouchard and Huneman 2013; Guay and Pradeu 2015). Statements like the following are not hard to find in the recent literature: 
Individuals can be defined anatomically, embryologically, physiologically, immunologically, genetically, or evolutionarily... each stems from the common tenet of genomic individuality: one genome/one organism. As such, all classical conceptions of individuality are called into question by evidence of all-pervading symbiosis. (Gilbert, Sapp, and Tauber 2012, 325).

It is not very reasonable to complain that DST has a more problematic conception of a biological individual than the traditional organism when that traditional conception of a population of physiologically integrated cells with a single genotype is itself so widely regarded as problematic! In the light of this, the initial response of Griffiths and Gray to this line of criticism continues to be effective. They argued that the idea of an individual organism was in fact quite problematic even at that time, and that DST did not need to offer a watertight account of the individuality of developmental processes in order to render itself a viable competitor to conventional accounts of the units of evolution and development (Griffiths and Gray 1994; Griffiths and Gray 2001).

Griffiths and Gray sketched how DST would approach the problem, using much of the same apparatus that biologists were already using to address problems with the traditional conception of an individual organism. They argued that a DST account of the individuality of developmental processes - what we are now calling genidentity - would define individuality in terms of the ability to act as a unit of selection (Griffiths and Gray 1994, 292-298; Griffiths and Gray 2001, 209-214). They drew on what were then current accounts of evolutionary individuality within the emerging framework of multi-level selection theory to suggest that, "an individual is a life cycle whose components cannot reconstruct themselves when decoupled from the larger cycle" (Griffiths and Gray 2001,213) and to recognize that, just like cells, organisms and superorganisms, life cycles might exist at several different levels of biological organization.

Looking back at theories of the organism in early $20^{\text {th }}$ century process biology, we can see a distinct similarity between Griffiths and Gray's ideas about the identity of developmental processes and Agar's idea that an organismic process is united by its 'subjective aim' or telos. A series of developmental events is a single process because they serve a common, evolutionary goal, namely to maximize the representation of cycles descended from them in future generations, relative to variant cycles with which they compete. We can draw on conventional evolutionary theory to make this suggestion a little more precise - an individual life cycle is a token of a life-history strategy, and that strategy is it telos and its principle of genidentity.

Life history theory is a powerful and remarkably general framework for addressing many basis questions about organismic design (Stearns 1992; Roff 2002). In life-history theory, the goal of an organism is to find the optimal way to parcel the resources available to it into offspring. This problem is modelled as the 
simultaneous optimisation of two parameters, the probability of surviving to each age class and the number of offspring produced in each age class, integrated across all age classes. The primary constraint on this optimisation problem is the quantity of resources available to the organism. But it is also constrained by multiple trade offs between the two key parameters: an overall trade-off between survival and reproduction; a trade-off between reproduction in the current age class and in later age classes; another between current reproduction and growth, between growth and survival to later age classes, and so forth. Solving this complex optimization problem under different sets of constraints and in different ecological settings leads to the many different life history strategies observed in nature. Since life history theory already conceives of an organism as a series of events (age classes) it is readily applicable to a life cycle consisting of a series of developmental interactions, each of which moves the lifecycle forward.

Life-history theory embodies a powerful principle of genidentity, because the evolutionary rationale for the choice of strategy at each life history stage is conditional on what choices have been or will be made at the other stages. A life cycle conceived of as the implementation of a life-history strategy is held together by the trade-offs between its stages. If these events were not part of a single life history serving a single, Darwinian telos, then they would not trade off against one another in this way. It makes sense for me to accept an elevated risk of cancer in later life in return for my increased reproductive success, but not for your reproductive success unless that is discounted by our coefficient of relationship. The life history strategy also defines where one process ends and another begins, namely at the points between which a single set of such trade offs exists. ${ }^{7}$ Life history theory also explains how life cycles that do not contain the same developmental events can nevertheless constitute a single lineage of cycles that succeeds in reproducing themselves. Adaptive phenotypic plasticity is part of a life-history strategy, and individuals who exhibit different developmental outcomes as a result of this plasticity are individuals who shared the same, plastic strategy.

Introducing a life-history perspective makes it clear why it is legitimate for developmental systems theorists to help themselves to whatever is currently the best evolutionary account of biological individuality ${ }^{8}$ and to 'process' that account. Evolutionary accounts of individuality seek to identify collections of biological material which are evolving as one: they are more or less successful in reproducing themselves as a whole, and that success cannot be reduced to the successes of each part of

\footnotetext{
${ }^{7}$ Life history theory in practice is conducted as a branch of population genetics, and we anticipate the objection that the implicit definition of the limits of an individual that we have made use of in this section is, in fact, derived from genetic identity. But this cannot be the case, as the theory applies perfectly well to asexual organisms whose parents and offspring are genetically identical to themselves. Moreover, so far as we can see, life-history theory could be extended unproblematically to cases in which heredity is epigenetic and exogenetic as well as genetic.

${ }^{8}$ For the current views of one author, see (Bourrat and Griffiths 2016)
} 
the whole, or the success of some larger whole of which this is a part. Admittedly, many discussions of this problem make it seem a matter of finding which spatial parts make a spatial whole. But this is an illusion - any such unit will, in fact, be extended in time and will embody a life-history strategy. DST will use this strategy to identify the events that make up a single, processual biological individual.

\section{Conclusions}

Developmental Systems Theory has a natural affinity with process views of the organism. The theorists who inspired and created DST all shared the view that development is a dynamic process whose study requires an investigation of it's dynamic form as well as the static constituents on which it draws. In Waddington's case this conviction was directly inspired by process philosophy. The idea of epigenesis, perhaps the single most important idea in the developmental systems tradition, is fundamentally processual. In development, something new comes into being that is not prefigured in any of the inputs to development. Dynamic interaction, another idea that has been central to all the major contributors to DST, is also essentially processual. The impact of a genetic or environmental factor at some point in development depends on how the organism has developed up to that point. Development is essentially a dynamic process and cannot be reduced to a list of ingredients and their interactions. The entities that make up a developmental system, which we can divide for some purposes into a genome, an epigenome and a developmental niche, are picked out as elements of a single system by the unity of the process to which they contribute, and not vice-versa. That principle of unity - the genidentity of a life cycle - we have argued, is simply its Darwinian telos - a life-history strategy.

\section{Acknowledgments}

"This project/publication was made possible through the support of a grant from the Templeton World Charity Foundation. The opinions expressed in this publication are those of the author(s) and do not necessarily reflect the views of the Templeton World Charity Foundation. We have benefited greatly from comments by Thomas Pradeu, Warwick Anderson, Peter Fairleigh and an anonymous referee."

\section{Bibliography}

Abir-Am, P. 1987. “The Biotheoretical Gathering, Trans-Disciplinary Authority and the Incipient Legitimation of Molecular Biology in the 1930s: New Perspective on the Historical Sociology of Science." History of Science 25 (1): 1-70. doi:10.1177/007327538702500101.

Agar, Wilfrid Eade. 1936. "Whitehead's Philosophy of Organism an Introduction for Biologists." The Quarterly Review of Biology 11 (1): 16-34.

\section{- - 1943. A Contribution to the Theory of the Living Organism. Melbourne: Melbourne University} Press in association with Oxford University Press. http://trove.nla.gov.au/version/37326004. Anderson, Warwick, and Ian R. Mackay. 2014. "Fashioning the Immunological Self: The Biological Individuality of F. Macfarlane Burnet." Journal of the History of Biology 47 (1): 147-75. doi:10.1007/s10739-013-9352-1. 
Bechtel, William, and Adele A. Abrahamsen. 2013. "Thinking Dynamically About Biological Mechanisms: Networks of Coupled Oscillators." Foundations of Science 18 (4): 707-23. doi:10.1007/s10699012-9301-z.

Birch, L. Charles. 1965. Nature and God. London: SCM Press.

Bouchard, Frédéric, and Philippe Huneman, eds. 2013. From Groups to Individuals: Evolution and

Emerging Individuality. Vienna Series in Theoretical Biology. Cambridge, Massachusetts: The MIT Press.

Bourrat, Pierrick, and Paul E. Griffiths. 2016. "Multi-Species Individuals." Under Review.

Bowler, Peter J. 2014. Reconciling Science and Religion: The Debate in Early-Twentieth-Century Britain.

University of Chicago Press.

Calcott, Brett, and Kim Sterelny, eds. 2011. The Major Transitions in Evolution Revisited. Vienna Series in Theoretical Biology. Cambridge, Mass: MIT Press.

Champagne, F.A., and J. P. Curley. 2009. "Epigenetic Mechanisms Mediating the Long-Term Effects of Maternal Care on Development." Neurosci Biobehav Rev 33 (4): 593-600.

Dawkins, R. 1976. The Selfish Gene. Oxford: Oxford University Press.

Denoël, Mathieu, Pierre Joly, and Howard H. Whiteman. 2005. "Evolutionary Ecology of Facultative Paedomorphosis in Newts and Salamanders." Biological Reviews of the Cambridge Philosophical Society 80 (4): 663-71. doi:10.1017/S1464793105006858.

Emmet, Dorothy. 1932. Whitehead's Philosophy of Organism. 1st ed. Palgrave MacMillan.

Ereshefsky, Marc, and Makmiller Pedroso. 2013. "Biological Individuality: The Case of Biofilms." Biology \& Philosophy 28 (2): 331-49. doi:10.1007/s10539-012-9340-4.

Ford, D. H., and R. M. Lerner. 1992. Developmental Systems Theory: An Integrative Approach. Newbury Park, CA: Sage.

French, Steven. 2012. "The Resilience of Laws." In Probabilities, Laws, and Structures, edited by Dennis Dieks, Wenceslao Gonzalex, Stephan Hartmann, Michael Stoltzner, and Marcel Weber. Springer Science \& Business Media.

Galef, B. G., and S. W. Wigmore. 1983. "Transfer of Information Concerning Distant Foods: A Laboratory Investigation of the 'Information-Centre' Hypothesis.” Anim. Behav. 31: 748-58.

Gilbert, Scott F., Jan Sapp, and Alfred I. Tauber. 2012. "A Symbiotic View of Life: We Have Never Been Individuals." The Quarterly Review of Biology 87 (4): 325-41. doi:10.1086/668166.

Godfrey-Smith, Peter. 2015. "Individuality and Life Cycles." In Individuals Across the Sciences, by Thomas Pradeu and Alexandre Guay, 85-102. NY and Oxford: Oxford University Press.

Goth, A. 2004. "Social Responses without Early Experience: Australian Brush-Turkey Chicks Use Specific Visual Cues to Aggregate with Conspecifics." Journal of Experimental Biology 207 (13): 2199-2208. doi:10.1242/jeb.01008.

Gottlieb, Gilbert. 1970. "Conceptions of Prenatal Behavior." In Development and Evolution of Behavior: Essays in Memory of T. C. Schneirla, edited by L. R. Aronson, E. Tobach, Daniel S Lehrman, and J. S. Rosenblatt, 111-37. San Francisco, CA: W. H. Freeman.

1997. Synthesizing Nature-Nurture : Prenatal Roots of Instinctive Behavior. Hillsdale, NJ: Lawrence Erlbaum Assoc.

2001. "A Developmental Psychobiological Systems View: Early Formulation and Current Status." In Cycles of Contingency: Developmental Systems and Evolution, edited by Susan Oyama, Paul E. Griffiths, and Russell D. Gray, 41-54. Cambridge, Mass.: MIT Press.

Gray, Russell D. 1992. “Death of the Gene: Developmental Systems Strike Back.” In Trees of Life: Essays in the Philosophy of Biology, edited by P. E. Griffiths, 165-210. Dordrecht: Kluwer.

Griffiths, Paul E, and Russell D Gray. 1994. "Developmental Systems and Evolutionary Explanation.” Journal of Philosophy XCI (6): 277-304.

——_. 1997. "Replicator II: Judgment Day." Biology and Philosophy 12 (4): 471-92.

-_- 2001. "Darwinism and Developmental Systems." In Cycles of Contingency: Developmental Systems and Evolution, edited by Susan Oyama, Paul E Griffiths, and Russell D Gray, 195-218. Cambridge, MA: MIT Press.

Griffiths, Paul E., and Russell D. Gray. 2005. "Three Ways to Misunderstand Developmental Systems Theory." Biology \& Philosophy 20 (2): 417-25.

Griffiths, Paul E, and Rob D Knight. 1998. "What Is the Developmentalist Challenge?" Philosophy of Science 65 (2): 253-58. 
Griffiths, Paul E., Arnaud Pocheville, Brett Calcott, Karola Stotz, Hyunju Kim, and Rob Knight. 2015. "Measuring Causal Specificity." Philosophy of Science 82 (4): 529-55.

Griffiths, Paul E, and Karola Stotz. 2013. Genetics and Philosophy: An Introduction. New York: Cambridge University Press.

Griffiths, Paul E, and James G Tabery. 2013. "Developmental Systems Theory: What Does It Explain, and How Does It Explain It?” In Embodiment and Epigenesis: Theoretical and Methodological Issues in Understanding the Role of Biology within the Relational Developmental System Part A: Philosophical, Theoretical, and Biological Dimensions, edited by Richard M Lerner and Janette B Benson, 45:6594. Advances in Child Development and Behavior 45. Elsevier.

Guay, Alexandre, and Thomas Pradeu, eds. 2015. Individuals Across the Sciences. Oxford University Press. Hall, Brian K. 2011. "A Brief History of the Term and Concept of Epigenetics." In Epigenetics: Linking Genotype and Phenotype in Develoment and Evolution, edited by Benedict Hallgrimsson and Brian K Hall, 9-13. Berkeley: University of California Press.

Hinde, R. A. 1968. "Dichotomies in the Study of Development." In Genetic and Environmental Influences on Behaviour, edited by J. M. Thoday and A. S. Parkes, 3-14. New York: Plenum.

Hull, David L. 1988. Science as a Process: An Evolutionary Account of the Social and Conceptual Development of Science. Chicago: Chicago University Press.

Jablonka, Eva, and Marion J. Lamb. 2005. Evolution in Four Dimensions: Genetic, Epigenetic, Behavioral, and Symbolic Variation in the History of Life. Cambridge, MA: The MIT Press.

Johnston, Timothy D. 1987. "The Persistence of Dichotomies in the Study of Behavioural Development." Developmental Review 7: 149-82.

Kitcher, P. 2001. "Battling the Undead: How (and How Not) to Resist Genetic Determinism." In Thinking about Evolution: Historical, Philosophical and Political Perspectives (Festchrifft for Richard Lewontin), edited by R. Singh, K. Krimbas, D. Paul, and J. Beatty, 396-414. Cambridge: Cambridge University Press.

Lande, R., and T. Price. 1989. "Genetic Correlations and Maternal Effect Coefficients Obtained from Offspring-Parent Regression.” Genetics 122: 915-22.

Lehrman, Daniel S. 1953. “Critique of Konrad Lorenz's Theory of Instinctive Behavior.” Quarterly Review of Biology 28: 337-63.

Lehrman, Daniel S. 1970. "Semantic \& Conceptual Issues in the Nature-Nurture Problem." In Development \& Evolution of Behaviour, edited by D. S. Lehrman, 17-52. San Francisco: W. H. Freeman and co.

Merlin, Francesca. 2010. "On Griffiths and Gray's Concept of Expanded and Diffused Inheritance." Biological Theory 5 (3): 206-15.

Moss, L. 1992. "A Kernel of Truth? On the Reality of the Genetic Program." Philosophy of Science Association Proceedings 1992 Vol.1: 335-48.

Nanney, D. L. 1958. "Epigenetic Control Systems.” Proc. Natl. Acad. Sci. 44: 712.

Noble, Denis. 2006. The Music of Life: Biology Beyod Genes. Oxford, UK: Oxford University Press.

Odling-Smee, F. John, Kevin N. Laland, and Marcus W. Feldman. 2003. Niche Construction: The Neglected Process in Evolution. Princeton, NJ: Princeton University Press.

Okasha, Samir. 2009. "Causation in Biology." In The Oxford Handbook of Causation, edited by Helen Beebee, Peter Menzies, and Christopher Hitchcock, 707-25. Oxford University Press.

Oyama, Susan. 1985. The Ontogeny of Information: Developmental Systems and Evolution. Cambridge: Cambridge University Press.

2000. "Causal Democracy and Causal Contributions in Developmental Systems Theory." Philosophy of Science (Supplement) 67: S332.

2002. "The Nurturing of Natures." In On Human Nature. Anthropological, Biological and Philosophical Foundations, edited by Armin Grunwald, Mathias Gutmann, and Eva M. NeumannHeld, 163-70. Studienreihe Der Europäischen Akademie. New York: Springer.

Peter Godfrey-Smith. 2000. "Explanatory Symmetries, Preformation, and Developmental Systems Theory." Philosophy of Science (Supplement) 67: S322-31.

Pradeu, Thomas. 2010. "The Organism in Developmental Systems Theory." Biological Theory 5 (3): 21622.

2012. The Limits of the Self: Immunology and Biological Identity. Translated by Elizabeth Vitanza. Oxford University Press. 
http://www.oxfordscholarship.com/view/10.1093/acprof:oso/9780199775286.001.0001/acpro f-9780199775286.

Robert, Jason S. 2004. Embryology, Epigenesis and Evolution: Taking Development Seriously. Cambridge: Cambridge University Press.

Robert, J. S., B. K. Hall, and W. M. Olson. 2001. "Bridging the Gap between Developmental Systems Theory and Evolutionary Developmental Biology." Bioessays 23 (October): 954-62.

Roff, D.A. 2002. Life History Evolution. New York: W H Freeman.

http://books.google.com.au/books?id=M_ZzQgAACAAJ.

Rosenberg, Alexander, and Daniel W. McShea. 2008. Philosophy of Biology: A Contemporary Introduction. New York and London: Routledge.

Stearns, Stephen C. 1992. The Evolution of Life Histories. 1 edition. Oxford ; New York: Oxford University Press.

Stegmann, Ulrich E. 2012. "Varieties of Parity." Biology \& Philosophy 27 (6): 903-18. doi:10.1007/s10539-012-9331-5.

Sterelny, Kim, Michael Dickison, and Kelly Smith. 1996. “The Extended Replicator.” Biology and Philosophy 11 (3): 377-403.

Stotz, Karola. 2006. "Molecular Epigenesis: Distributed Specificity as a Break in the Central Dogma'." History and Philosophy of the Life Sciences 28: 533-48.

_- _. 2008. "The Ingredients for a Postgenomic Synthesis of Nature and Nurture." Philosophical Psychology 21: 359-81.

. 2010. "Human Nature and Cognitive-Developmental Niche Construction." Phenomenology and the Cognitive Sciences 9: 483-501.

Stotz, Karola, and Colin Allen. 2012. "From Cell-Surface Receptors to Higher Learning: A Whole World of Experience." In Philosophy of Behavioural Biology, edited by Katie Plaisance and Thomas Reydon, 85-123. Boston Studies in Philosophy of Science. Boston, MA: Springer.

Stotz, Karola, and Paul E. Griffiths. In Press. "Genetic, Epigenetic and Exogenetic Information." In Routledge Handbook of Evolution and Philosophy, by Richard Joyce. London \& New York: Routledge.

Tabery, James G. 2009. “Difference Mechanisms: Explaining Variation with Mechanisms.” Biology and Philosophy 21 (5): 645-64.

Thelen, E, and L Smith. 1994. A Dynamic Systems Approach to the Development of Cognition and Action. Cambridge, M.A: MIT Press.

Thornhill, Randy. 2007. "The Importance of Developmental Biology to Evolutionary Biology and Vice Versa." In The Evolution of Mind: Fundamental Questions and Controversies, edited by Steven W Gangestad and Jeffry A Simpson. New York, NY: Guilford Publications.

Thorpe, William Horman. 1956. Learning and Instinct in Animals. Cambridge, MA: Harvard University Press.

Waddington, Conrad H. 1942. "The Epigenotype." Endeavour 1: 18-20.

Waddington, Conrad H. 1952. "The Evolution of Developmental Systems." In Proceedings of the TwentyEighth Meeting of the Australian and New Zealand Association for the Advancement of Science, edited by D.A Herbert, 155-59. Brisbane, Australia: A.H Tucker, Government Printer.

Waddington, Conrad Hal. 1975. The Evolution of an Evolutionist. Edinburgh University Press.

Wade, Michael J. 1998. "The Evolutionary Genetics of Maternal Effects." In Maternal Effects as Adaptations, P. 5-21, edited by Timothy A. Mousseau and Charles W. Fox. Oxford: Oxford University Press. Waters, C. Kenneth. 2007. “Causes That Make a Difference." Journal of Philosophy 104 (11): 551-79. Weber, Marcel. 2006. "The Central Dogma as a Thesis of Causal Specificity." History and Philosophy of the Life Sciences 28 (4): 595-609.

West, Meredith J., and Andrew P. King. 1987. "Settling Nature and Nurture into an Ontogenetic Niche." Developmental Psychobiology 20: 549-62.

. 2008. "Deconstructing Innate Illusions: Reflections on Nature-Nurture-Niche from an Unlikely

Source." Philosophical Psychology 21: 383-95.

West, Meredith J., Andrew P. King, and Anne A. Arberg. 1988. “The Inheritance of Niches.” In Developmental Psychobiology and Behavioral Ecology, edited by E. M. Blass. Vol. 9. Handbook of Behavioral Neurobiology. New York and London: Plenum Press. 
Wilkins, Adam. 2011. "Epigenetic Inheritance: Where Does the Field Stand Today? What Do We Still Need to Know?" In Transformations of Lamarckism: From Subtle Fluids to Molecular Biology, edited by Snait B. Gissis and Eva Jablonka, 389-93. Cambridge, MA: The MIT Press.

Williams, George C. 1992. Natural Selection: Domains, Levels and Challenges. New York: Oxford University Press.

Woodward, James. 2011. "Causes, Conditions, and the Pragmatics of Causal Explanation." In Philosophy of Science Matters: The Philosophy of Peter Achinstein, 247-57. Oxford and New York: Oxford University Press. 